\title{
Ultrasonography and 3D-CT Follow-Up of Extrahepatic Portal Vein Aneurysm: A Case Report
}

\author{
Norio Yukawa, ${ }^{1,2}$ Makoto Takahashi, ${ }^{1}$ Kazuyoshi Sasaki, ${ }^{1}$ Takuma Mori, ${ }^{1}$ \\ Ayumi Matsuo, ${ }^{1}$ Kuniyasu Ito, ${ }^{1}$ Hiroyuki Kirikoshi, ${ }^{3}$ Kiyoshi Ohya, ${ }^{1}$ Nobuyuki Wada, ${ }^{2}$ \\ Yasushi Rino, ${ }^{2}$ and Munetaka Masuda ${ }^{2}$ \\ ${ }^{1}$ Kamishirane Hospital, 2-65-1 Kamishirane, Asahi-ku, Yokohama 241-0002, Japan \\ ${ }^{2}$ Department of Surgery, Yokohama City University, 3-9 Fukuura, Kanazawa-ku, Yokohama, 236-0004, Japan \\ ${ }^{3}$ Department of Gastroenterology, Yokohama City University, Yokohama, 236-0004, Japan
}

Correspondence should be addressed to Norio Yukawa, nryukawa@mac.com

Received 11 March 2010; Accepted 28 April 2010

Academic Editor: Peter M. Van Ooijen

Copyright (C 2010 Norio Yukawa et al. This is an open access article distributed under the Creative Commons Attribution License, which permits unrestricted use, distribution, and reproduction in any medium, provided the original work is properly cited.

\begin{abstract}
Extrahepatic portal vein aneurysm is a rare disorder. From 1956 to 2008, we found only 43 published English-language reports, including 67 cases, using Pub Med. We report a case of a 77-year-old woman who had complaints of lower abdominal fullness and residual urine. We performed ultrasonography (US), which demonstrated a congenital extrahepatic portal vein aneurysm. She had no obvious symptoms of the extrahepatic portal vein aneurysm. She had undergone gastrectomy without blood transfusion for gastric ulcer more than 20 years ago. Physical examination revealed no abnormal findings. US revealed a $2.2 \times 1.8 \mathrm{~cm}$, round shaped hypoechogenic lesion at the hepatic hilum. Color Doppler US showed bidirectional colors due to circular flow within this lesion. 3D-CT and CT angiography demonstrated that the saccular aneurysm at the hepatic hilum was $3.0 \mathrm{~cm}$ in diameter and was enhanced equal to that of portal vein. Twenty-six months after the diagnosis, the aneurysm had not grown in size. Since our patient had no serious complaints or liver disease, surgical procedures had not been employed. US and 3D-CT are noninvasive diagnostic techniques and are helpful in the diagnosis and follow-up of extrahepatic portal vein aneurysms.
\end{abstract}

\section{Case report}

A 77-year-old Japanese woman had been hospitalized in our institute due to urocystitis. In September 2007, she was incidentally diagnosed with a congenital extrahepatic portal vein aneurysm after Ultrasonography (US) was conducted during an investigation for lower abdominal fullness and residual urine. She had undergone gastrectomy due to gastric ulcer without blood transfusion. Her family history was not particularly interesting. Physical examination revealed no jaundice, no abdominal mass, and no vascular noise. Routine blood tests did not show any remarkable findings. US revealed a well-circumscribed anechoic structure that was $26.4 \times 21.7 \times 19.4 \mathrm{~mm}$ in size at the porta hepatis (Figures 1(a), 1(b), and 1(c)). Color Doppler US demonstrated bidirectional color due to circular flow within the aneurysm (Figure 1(d)). Abdominal enhanced 3D-CT and
CT angiography demonstrated that the saccular aneurysm at the hepatic hilum was $30 \mathrm{~mm}$ in diameter and was enhanced equal to that of portal vein (Figures 2(a), 2(b), and 2(c)). CT angiography demonstrated a common iliac artery aneurysm (Figure 2(d)).

She remained asymptomatic and returned to the hospital 26 months after the diagnosis for follow-up. The aneurysm showed no enlargement in size by follow-up CT and US after 27 months.

\section{Discussion}

Portal vein aneurysm (PVA) is an uncommon disease [1, $2]$. However, recently, the number of reported cases has gradually increased with advances in imaging techniques. Koc et al. [3] reported 25 PVA cases in 4186 patients using abdominal CT and US. PVAs are classified as intrahepatic and extrahepatic. Our case was diagnosed as extrahepatic 
TABLE 1: Summary of the reported cases of portal vein aneurysm in English litelature (including our case).

\begin{tabular}{|c|c|c|c|c|c|}
\hline Sex & & & & Liver disorder & \\
\hline Male & & 23 & & positive & 21 \\
\hline Female & & 44 & Total 68 & negative & 45 \\
\hline unknown & & 1 & & unknown & 2 \\
\hline \multirow[t]{3}{*}{ Age } & $51.4(0 \sim 83)$ & & & Portal hypertension & \\
\hline & & & & positive & 23 \\
\hline & & & & negative & 45 \\
\hline Size & & & Size $(\mathrm{cm})$ & Congenital or acquired & \\
\hline Extrahepatic & 67 & & average & congenital & 39 \\
\hline \multirow[t]{2}{*}{ Extra-Intrahepatic } & 1 & & $4.36(0.8 \sim 11.5)$ & acquired & 5 \\
\hline & & & & unknown & 24 \\
\hline \multicolumn{6}{|l|}{ Shape } \\
\hline cyst-form & 36 & & $4.20(0.8 \sim 11.5)$ & & \\
\hline fusiform & 22 & & $4.62(0.8 \sim 8.0)$ & & \\
\hline unknown & 11 & & & & \\
\hline Symptoms & & & & Past history & \\
\hline Abdominal or back pain & 34 & & & $\begin{array}{l}\text { hepatitis, liver cirrhosis, } \\
\text { HCC }\end{array}$ & 12 \\
\hline nausea, vomiting & 6 & & & esophageal varix & 4 \\
\hline hematemesis, melena & 3 & & & $\begin{array}{l}\text { gallstone, } \\
\text { cholecystectomy }\end{array}$ & 5 \\
\hline fever up & 4 & & & hysterectomy & 2 \\
\hline jaundice & 4 & & & $\begin{array}{l}\text { Malignancy (exclude } \\
\text { HCC) }\end{array}$ & 3 \\
\hline liver disorder & 1 & & & gastric ulcer & 2 \\
\hline indigestion & 1 & & & gastrectomy & 2 \\
\hline rapture & 1 & & & pancreatitis & 1 \\
\hline hematuria & 1 & & & arthritis & 1 \\
\hline abdominal discomfort & 1 & & & hypertension & 2 \\
\hline splenomegaly & 1 & & & diabetes mellitus & 1 \\
\hline chorecystitis & 1 & & & $\begin{array}{l}\text { idiopathic portal } \\
\text { hypertension }\end{array}$ & 1 \\
\hline none & 19 & & & hyperammoninemia & 1 \\
\hline \multirow[t]{8}{*}{ unknown } & 1 & & & lower extremity varix & 1 \\
\hline & *including overlap & & & $\begin{array}{l}\text { non-chirrhotic portal } \\
\text { fibrosis }\end{array}$ & 1 \\
\hline & & & & schistosomiasis & 1 \\
\hline & & & & myocardial infarction & 1 \\
\hline & & & & SLE & 1 \\
\hline & & & & none & 34 \\
\hline & & & & unknown & 1 \\
\hline & & & & & $\begin{array}{l}* \text { including } \\
\text { overlap }\end{array}$ \\
\hline
\end{tabular}


Table 1: Continued.

\begin{tabular}{|c|c|c|c|}
\hline \multicolumn{2}{|l|}{ Tool of diagnosis } & \multicolumn{2}{|l|}{ Treatment } \\
\hline ultrasonography & 48 & none & 46 \\
\hline CT & 43 & operation & 19 \\
\hline angiography & 21 & $\begin{array}{l}\text { Angiography, } \\
\text { embolization }\end{array}$ & 2 \\
\hline MRI & 14 & unknown & 1 \\
\hline scintigram & 2 & Clinical course & \\
\hline none & 2 & good course & 58 \\
\hline autopsy & 1 & dead & 7 \\
\hline \multirow[t]{2}{*}{ unknown } & 1 & unknown & 3 \\
\hline & *including overlap & & \\
\hline
\end{tabular}

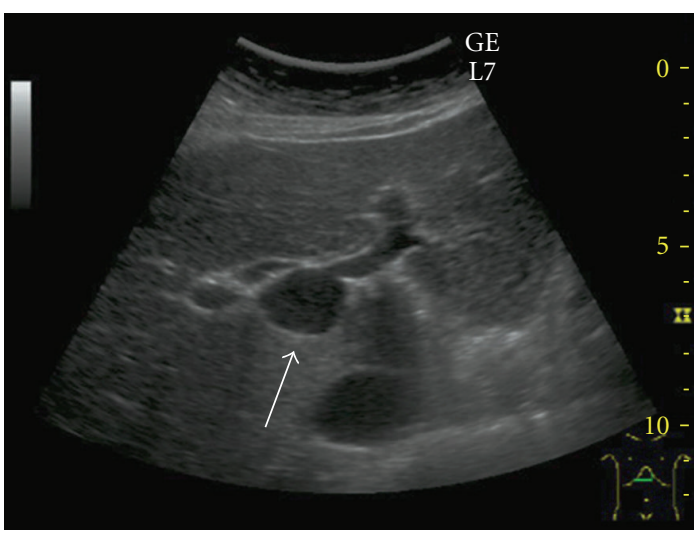

(a)

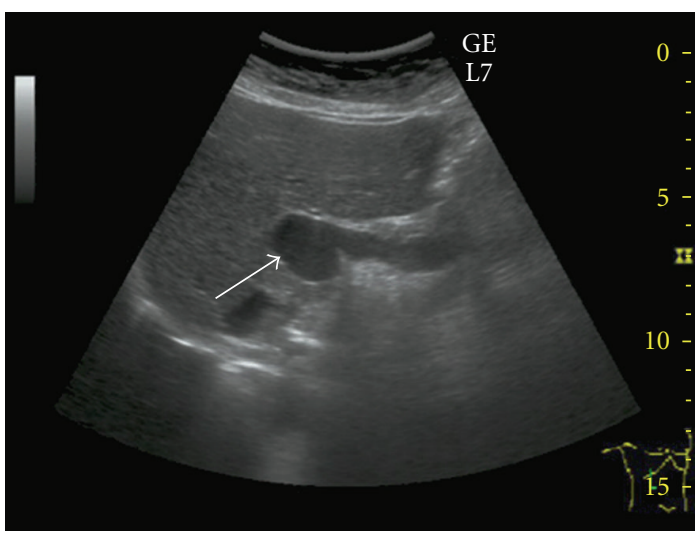

(c)

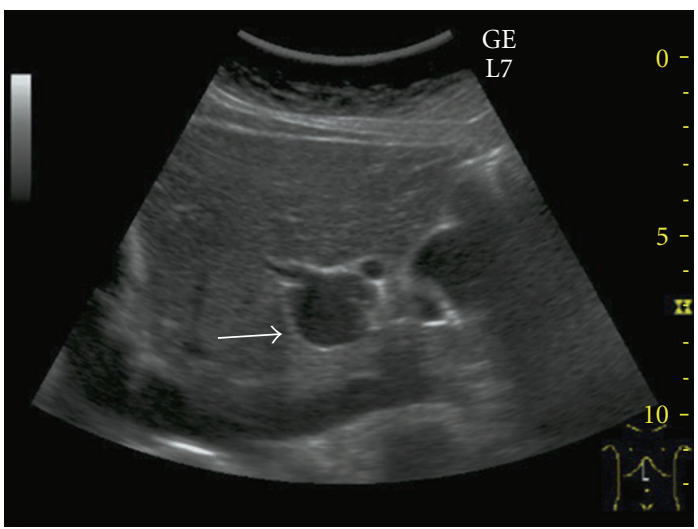

(b)

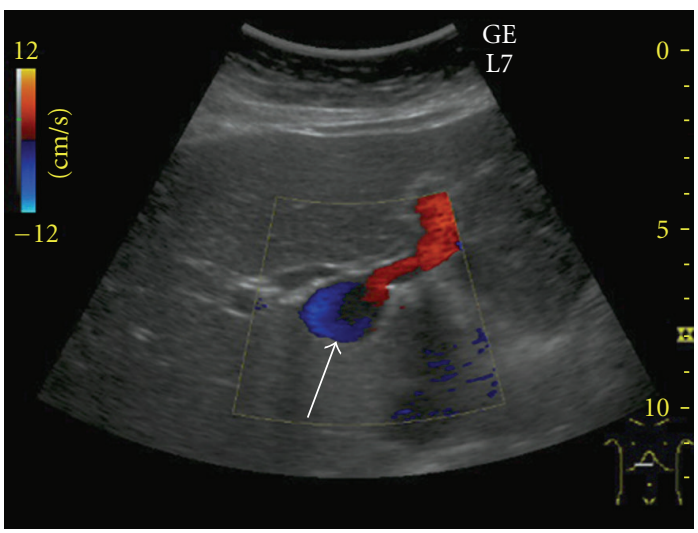

(d)

FIgURE 1: (a), (b), and (c) Ultrasonography (US) revealed a well-circumscribed anechoic structure that was $26.4 \times 21.7 \times 19.4 \mathrm{~mm}$ in size at the porta hepatis (white arrow). (d) Color Doppler US demonstrated bidirectional color due to circular flow within the aneurysm.

PVA. Sixty-seven cases of extrahepatic PVAs were reported in the English literature from 1956 to 2008 [1-44]. Including our case, we summarized 68 PVA cases (Table 1). Twentythree males, 44 females, and one unknown were reported. Their mean age was 51.4 years (range $0-83$ years), and the mean size was $43.6 \mathrm{~mm}$ (range $8-115 \mathrm{~mm}$ ). The cyst-form was found in 36 cases and the fusiform was found in 22 cases (unknown 11 cases). Half of all cases complained of abdominal or back pain. Nineteen cases had no symptoms. Twenty-one patients showed liver dysfunction in blood 


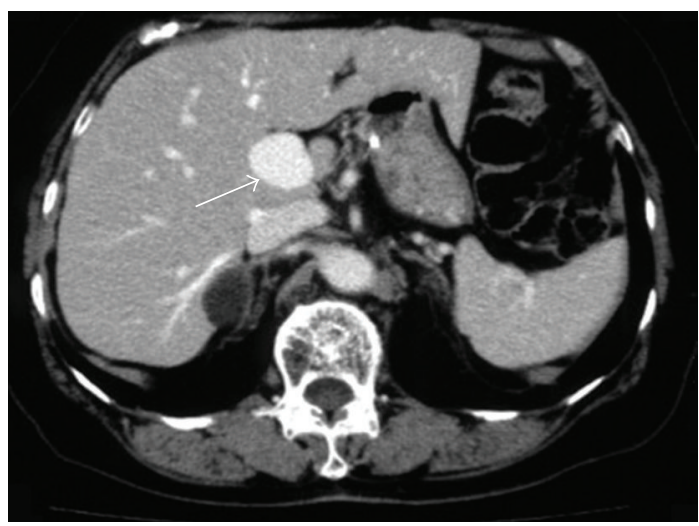

(a)

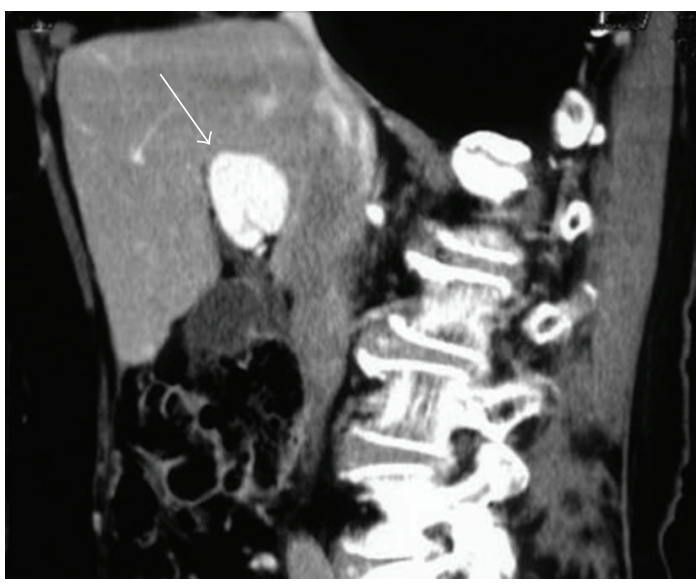

(c)

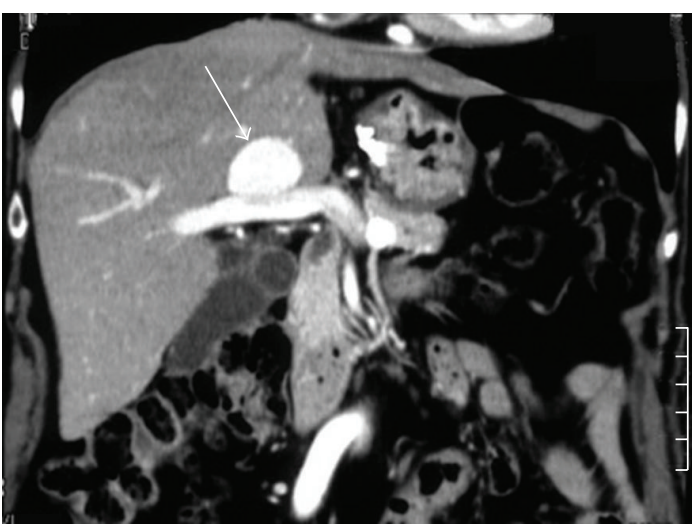

(b)

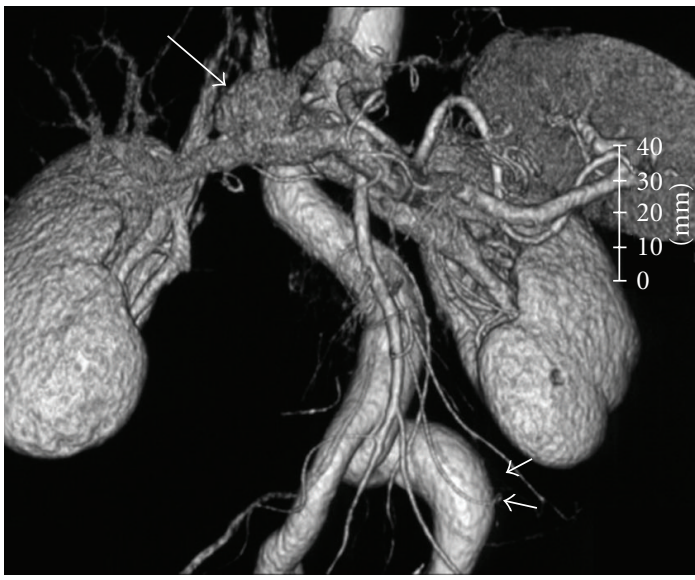

(d)

Figure 2: 3D-CT (a) horizontal view, (b) coronary view, and (c): sagittal view and CT angiography (d) demonstrated that the saccular aneurysm at the hepatic hilum was $30 \mathrm{~mm}$ in diameter and was enhanced equal to that of the portal vein (white arrow). CT angiography demonstrated left common iliac artery aneurysm (white arrow head).

examination, and only 23 had portal hypertension. Half of all cases had no past history. Nineteen patients had undergone operation, 2 had undergone embolization by angiography, and 46 were observed clinically. Fifty-eight cases had a good course, while 7 were dead. Previously, most patients with asymptomatic PVAs were managed by observation [44]. Recently, several reports have suggested that operation can be performed easily and safely $[1,44]$. The operation may be one of the therapeuticprocedures for PVAs with any symptoms or complications.

The origin of PVAs may be congenital or acquired [37]. Formerly, cases of PVA with liver disorder, portal hypertension, trauma, or pancreatitis were reported, but recently congenital PVA cases have been reported without these diseases, due to advances in imaging $[1,6]$. Our case was considered to be congenital PVA due to the absence of past history and the presence of common iliac artery aneurysm.

Abdominal US (including Doppler US) is useful and convenient for the diagnosis of PVA and has been used in most cases to date $[8,9,34]$. About $70 \%$ of reported extra PVAs had undergone US. By contrast, angiography can describe PVA collectively and clearly [31, 32] but is not indispensable because of its invasive nature. In place of angiography, MRI (including MR-angio) has been used increasingly [5]. Our patient had undergone gastrectomy twenty years ago and stainless staples remained in the abdomen. Because of those staples, 3D-CT was selected to describe a solid image of the whole portal vein system. 3DCT can show the size and location of PVA in stereoimages. Repeatability is high without interoperator variability and may confirm the diagnosis and the observation of PVA.

\section{References}

[1] S. W. Cho, J. W. Marsh, P. A. Fontes, M. F. Daily, M. Nalesnik, M. Tublin, M. E. De Vera, D. A. Geller, and T. C. Gamblin, "Extrahepatic portal vein aneurysm-report of six patients and review of the literature," Journal of Gastrointestinal Surgery, vol. 12, no. 1, pp. 145-152, 2008.

[2] H.-F. Luo, H.-J. Wang, B. Li, and Z.-Y. Wang, "Diagnosis and management of extrahepatic portal vein aneurysm: a case report," Hepatobiliary and Pancreatic Diseases International, vol. 5, no. 2, pp. 311-313, 2006. 
[3] Z. Koc, L. Oguzkurt, and S. Ulusan, "Portal venous system aneurysms: imaging, clinical findings, and a possible new etiologic factor," American Journal of Roentgenology, vol. 189, no. 5, pp. 1023-1030, 2007.

[4] E. López-Machado, F. Mallorquín-Jiménez, A. MedinaBenítez, E. Ruiz-Carazo, and M. Cubero-García, "Aneurysms of the portal venous system: ultrasonography and CT findings," European Journal of Radiology, vol. 26, no. 2, pp. 210 214, 1998.

[5] B. Jin, Y. Sun, Y.-Q. Li, Y.-G. Zhao, C.-S. Lai, X.-S. Feng, and C.-D. Wan, "Extrahepatic portal vein aneurysm: two case reports of surgical intervention," World Journal of Gastroenterology, vol. 11, no. 14, pp. 2206-2209, 2005.

[6] A. M. De Gaetano, M. C. Andrisani, B. Gui, G. Maresca, R. Ionta, and L. Bonomo, "Thrombosed portal vein aneurysm," Abdominal Imaging, vol. 31, no. 5, pp. 545-548, 2006.

[7] C. Giavroglou, E. Xinou, and N. Fotiadis, "Congenital extrahepatic portal vein aneurysm," Abdominal Imaging, vol. 31, no. 2, pp. 241-244, 2006.

[8] Y. Ohnami, H. Ishida, K. Konno, H. Naganuma, Y. Hamashima, A. Zeniya, and O. Masamune, "Portal vein aneurysm: report of six cases and review of the literature," Abdominal Imaging, vol. 22, no. 3, pp. 281-286, 1997.

[9] A. Fulcher and M. Turner, "Aneurysms of the portal vein and superior mesenteric vein," Abdominal Imaging, vol. 22, no. 3, pp. 287-292, 1997.

[10] T. V. Thomas, "Aneurysm of the portal vein: report of two cases, one resulting in thrombosis and spontaneous rupture," Surgery, vol. 61, no. 4, pp. 550-555, 1967.

[11] R. Barzilai and M. S. Kleckner Jr., "Hemocholecyst following ruptured aneurysm of portal vein; report of a case," AMA Archives of Surgery, vol. 72, no. 2, pp. 725-727, 1956.

[12] C. E. Sedgwick, "Cisternal dilatation of portal vein associated with portal hypertension and partial biliary obstruction," The Lahey Clinic bulletin, vol. 11, pp. 234-237, 1960.

[13] A. L. Leonsins and S. Siews, "Fusiform aneurysmal dilatation of the portal vein," Postgraduate Medical Journal, vol. 36, pp. 570-574, 1960.

[14] R. E. Hermann and W. H. Shafer, "Aneurysm of the portal vein and portal hypertension: first reported case," Annals of Surgery, vol. 162, no. 6, pp. 1101-1104, 1965.

[15] H. R. Liebowitz and L. M. Rousselot, "Saccular aneurysm of portal vein with agnogenic myeloid metaplasia," New York State Journal of Medicine, vol. 67, no. 11, pp. 1443-1447, 1967.

[16] H. S. Vine, J. C. Sequeira, W. C. Widrich, and B. A. Sacks, "Portal vein aneurysm," American Journal of Roentgenology, vol. 132, no. 4, pp. 557-560, 1979.

[17] R. A. Kane and S. G. Katz, "The spectrum of sonographic findings in portal hypertension: a subject review and new observations," Radiology, vol. 142, no. 2, pp. 453-458, 1982.

[18] M. Boyez, Y. Fourcade, A. Sebag, and M. Valette, "Aneurysmal dilatation of the portal vein: a case diagnosed by real-time ultrasonography," Gastrointestinal Radiology, vol. 11, no. 4, pp. 319-321, 1986.

[19] P. B. Thompson, K. T. Oldham, and D. G. Bedi, "Aneurysmal malformation of the extrahepatic portal vein," American Journal of Gastroenterology, vol. 81, no. 8, pp. 695-697, 1986.

[20] K. Andoh, K. Tanohata, K. Asakura, Y. Katsumata, T. Nagashima, and F. Kitoh, "CT demonstration of portal vein aneurysm," Journal of Computer Assisted Tomography, vol. 12, no. 2, pp. 325-327, 1988.

[21] H.-C. Lee, Y. C. Yang, S.-L. Shih, and H.-J. Chiang, "Aneurysmal dilatation of the portal vein," Journal of Pediatric Gastroenterology and Nutrition, vol. 8, no. 3, pp. 387-389, 1989.
[22] B. K. Baker and J. A. Nepute, "Computed tomography demonstration of acute thrombosis of a portal vein aneurysm," Missouri medicine, vol. 87, no. 4, pp. 228-230, 1990.

[23] H. Hagiwara, A. Kasahara, M. Kono, S. Kashio, A. Kaneko, A. Okuno, N. Hayashi, H. Fusamoto, and T. Kamada, "Extrahepatic portal vein aneurysm associated with a tortuous portal vein," Gastroenterology, vol. 100, no. 3, pp. 818-821, 1991.

[24] L. Dognini, A. L. Carreri, and G. Moscatelli, "Aneurysm of the portal vein: ultrasound and computed tomography identification," Journal of Clinical Ultrasound, vol. 19, no. 3, pp. 178-182, 1991.

[25] H. Fukui, T. Kashiwagi, K. Kimura, M. Goto, Y. Takei, A. Kasahara, S. Kawano, H. Fusamoto, T. Kozuka, and T. Kamada, "Portal vein aneurysm demonstrated by blood pool SPECT," Clinical Nuclear Medicine, vol. 17, no. 11, pp. 871-873, 1992.

[26] S. Savastano, G. P. Feltrin, I. Morelli, D. Miotto, M. ChiesuraCorona, and A. B. El Khatib, "Aneurysm of the extrahepatic portal vein associated with segmental portal hypertension and spontaneous porto-caval shunting through the inferior mesenteric vein," Journal Belge de Radiologie, vol. 75, no. 3, pp. 194-196, 1992.

[27] S. Glazer, M. R. Gaspar, V. Esposito, and L. Harrison, "Extrahepatic portal vein aneurysm: report of a case treated by thrombectomy and aneurysmorrhaphy," Annals of Vascular Surgery, vol. 6, no. 4, pp. 338-342, 1992.

[28] H. M. Malde and D. Chadha, "Extrahepatic portal vein aneurysm in non-cirrhotic portal fibrosis," Australasian Radiology, vol. 37, no. 2, pp. 221-222, 1993.

[29] Y. Itoh, T. Kawasaki, H. Nishikawa, J. Ochi, K. Miura, and F. Moriyasu, "A case of extrahepatic portal vein aneurysm accompanying lupoid hepatitis," Journal of Clinical Ultrasound, vol. 23, no. 6, pp. 374-378, 1995.

[30] T. Miyazaki, Y. Yamashita, K. Tomoda, T. Matsukawa, M. Harada, H. Yamamoto, A. Arakawa, and M. Takahashi, "Transarterial embolization of an extrahepatic portal vein aneurysm with arterioportal fistula," CardioVascular and Interventional Radiology, vol. 18, no. 3, pp. 189-191, 1995.

[31] P. D. Feliciano, J. J. Cullen, and J. D. Corson, "The management of extrahepatic portal vein aneurysms: observe or treat?" HPB Surgery, vol. 10, no. 2, pp. 113-116, 1996.

[32] P. A. Brock, P. H. Jordan Jr., M. H. Barth, and A. G. Rose, "Portal vein aneurysm: a rare but important vascular condition," Surgery, vol. 121, no. 1, pp. 105-108, 1997.

[33] S. Tsukuda, E. Sugimoto, T. Watabe, M. Amanuma, and A. Heshiki, "A case of extrahepatic portal vein aneurysm with massive thrombosis: diagnosis with reconstruction images from helical CT scans," Radiation Medicine, vol. 16, no. 4, pp. 301-303, 1998.

[34] K. C. Atasoy, S. Fitoz, G. Akyar, S. Aytaç, and I. Erden, "Aneurysms of the portal venous system: gray-scale and color Doppler ultrasonographic findings with CT and mri correlation," Clinical Imaging, vol. 22, no. 6, pp. 414-417, 1998.

[35] M. I. Oliver and R. Calpena, "Images in hepatology. Extrahepatic portal vein aneurysm," Journal of hepatology, vol. 28, no. 1, p. $168,1998$.

[36] J.-W. Huang, M.-S. Wu, T.-S. Chu, and T.-J. Tsai, "Hepatic aneurysm and portal vein thrombosis in a patient with lupus erythematosus on dialysis," Nephrology Dialysis Transplantation, vol. 14, no. 3, pp. 753-756, 1999.

[37] R. Blasbalg, R. M. Yamada, and D. A. Tiferes, "Extrahepatic portal vein aneurysms," American Journal of Roentgenology, vol. 174 , no. 3 , p. $877,2000$. 
[38] H. Lau, D. K. Chew, and M. Belkin, "Extrahepatic portal vein aneurysm: a case report and review of the literature," Cardiovascular Surgery, vol. 10, no. 1, pp. 58-61, 2002.

[39] K. Arda, K. T. Kizilkanat, Ö. Tosun, and D. Öğdüm, "Portal vein aneurysm; CT, MR and MR angiography appearances," Acta Gastro-Enterologica Belgica, vol. 65, no. 2, pp. 136-138, 2002.

[40] P. Santana, R. B. Jeffrey Jr., and A. Bastidas, "Acute thrombosis of a giant portal venous aneurysm: value of color Doppler sonography," Journal of Ultrasound in Medicine, vol. 21, no. 6, pp. 701-704, 2002.

[41] T. Mhanna, P. Bernard, F. Pilleul, and C. Partensky, "Portal vein aneurysm: report of two cases," Hepato-Gastroenterology, vol. 51, no. 58, pp. 1162-1164, 2004.

[42] R. Gomez, D. M. Bentsen, and R. S. Burd, "Antenatal diagnosis of an extrahepatic portal vein aneurysm," Southern Medical Journal, vol. 97, no. 10, pp. 1023-1024, 2004.

[43] J. Kim, M.-J. Kim, S. Y. Song, J. H. Kim, J. S. Lim, Y. T. Oh, and K. W. Kim, "Acute thrombosis of a portal vein aneurysm and development," Clinical Radiology, vol. 59, no. 7, pp. 631-633, 2004.

[44] M. Wolff, N. Schaefer, J. Schmidt, and A. Hirner, "Thrombosis of a large portal vein aneurysm: treatment by thrombectomy, aneurysmorrhaphy, and portocaval shunt," Journal of Gastrointestinal Surgery, vol. 10, no. 1, pp. 128-131, 2006. 


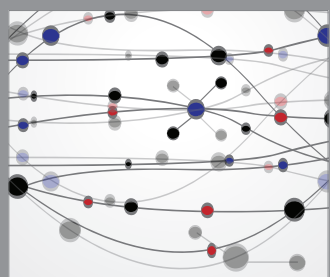

The Scientific World Journal
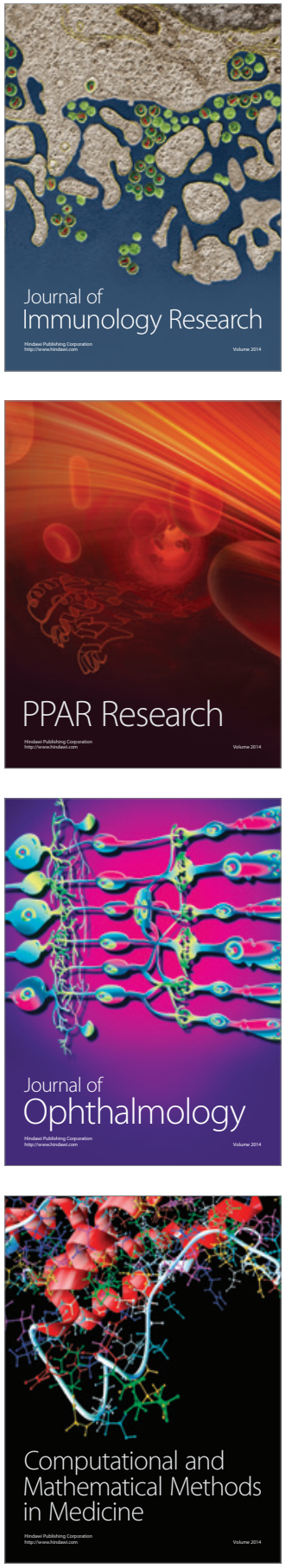

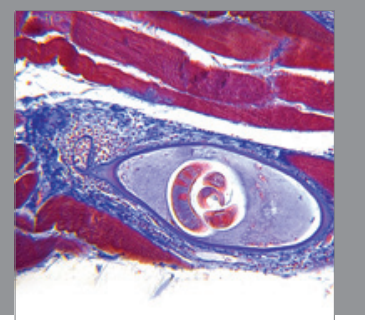

Gastroenterology

Research and Practice
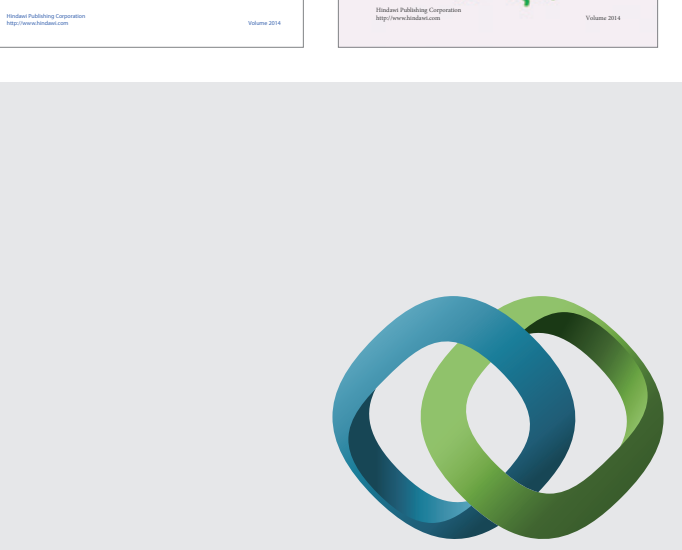

\section{Hindawi}

Submit your manuscripts at

http://www.hindawi.com
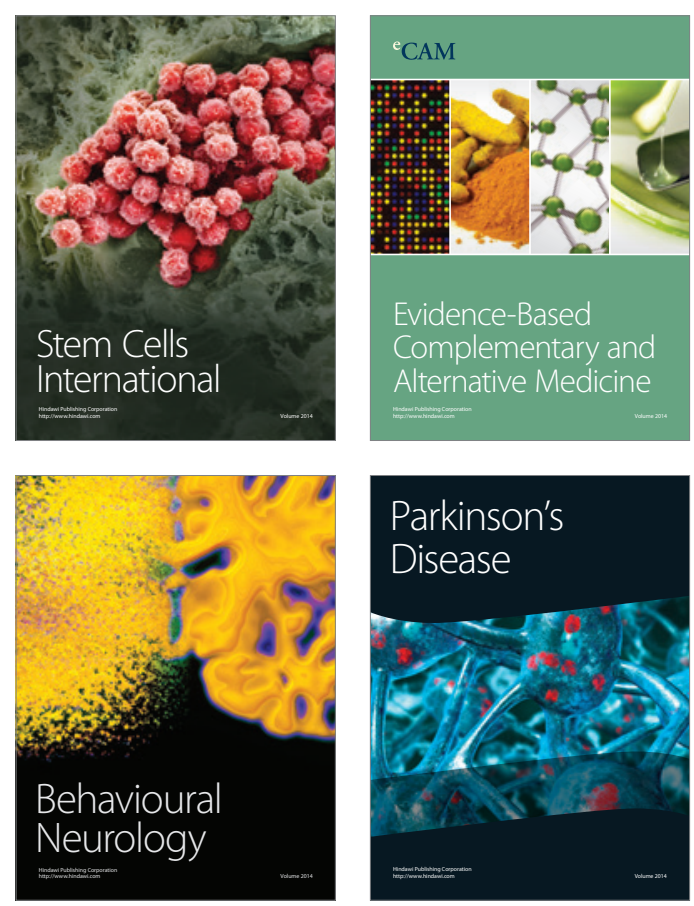

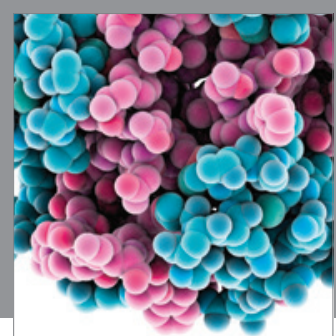

Journal of
Diabetes Research

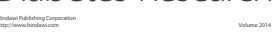

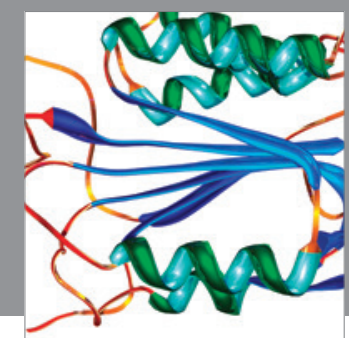

Disease Markers
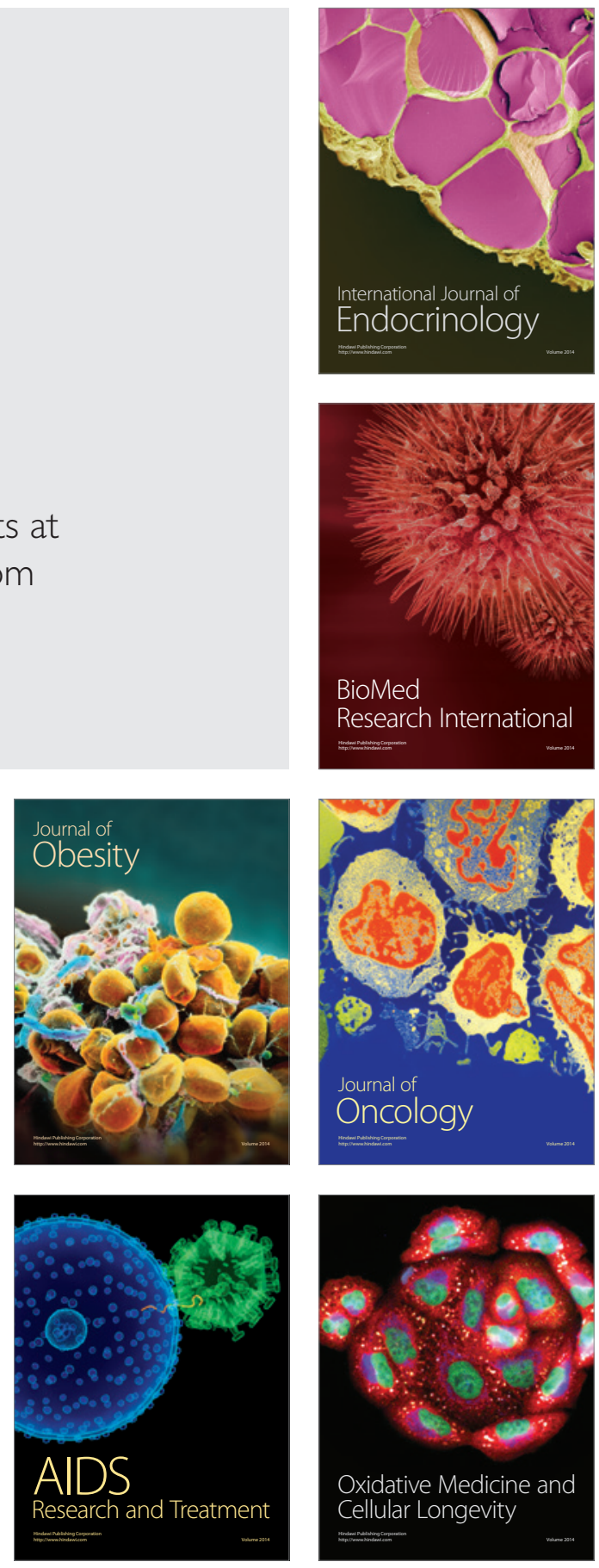